\title{
Research on the Impact of Chinese Total Factor Productivity on the Modern Economic System Based on the Spatial Dubin Model
}

\author{
Qin Tang $\mathbb{D}^{1},{ }^{1}$ Zhi-An Ren ${ }^{(D)},{ }^{1}$ Kang-Feng Zhu $\mathbb{D}^{1},{ }^{1}$ and Nai-Ru Xu $\mathbb{D}^{2}$ \\ ${ }^{1}$ School of Economics, Anhui University of Finance and Economics, Bengbu 233030, China \\ ${ }^{2}$ School of Business, Anhui Xinhua University, Hefei 230088, China \\ Correspondence should be addressed to Nai-Ru Xu; xunairu@163.com
}

Received 5 August 2021; Accepted 23 August 2021; Published 29 August 2021

Academic Editor: Shaohui Wang

Copyright (c) 2021 Qin Tang et al. This is an open access article distributed under the Creative Commons Attribution License, which permits unrestricted use, distribution, and reproduction in any medium, provided the original work is properly cited.

Total factor productivity is not only the core of high-quality economic development but also a core indicator for measuring the quality of economic development. Improving total factor productivity is one of the most critical points in building a modern economic system. Firstly, this paper uses the DEA-Malmquist index method to measure and decompose the total factor productivity of China's 30 provinces, municipalities, and autonomous regions from 2001 to 2017 and analyzes the characteristics of its temporal and spatial changes. From a spatial perspective, the regional gap is relatively large. Secondly, we construct the index system of five dimensions and use this index system to comprehensively evaluate the improvement degree of China's modernized economic system. The results show that the overall level of the improvement degree of China's modernized economic system is relatively low, and the differences between provinces are great. Thirdly, this paper uses static and dynamic spatial econometric models to empirically analyze the effect of total factor productivity on the improvement degree of the modern economic system. The results show that the improvement degree of the modern economic system in China has obvious characteristics of time spillover and space spillover. Finally, we put forward countermeasures and suggestions on how to perfect the modern economic system.

\section{Introduction}

Building a modern economic system is a major strategic goal and task facing our country's economy after it has entered an era of high-quality development from the era of rapid growth. The report of the 19th National Congress of the Communist Party of China clearly pointed out that our country's economy is in a critical period of transition from old to new growth momentum. In view of the current domestic and foreign economic environment in my country, the report proposed for the first time the establishment of a "modern economic system." The development of the economic system framework has been summarized. The construction of a modern economic system includes three levels: a modern power system, an industrial system, and an economic system under the guidance of the new development concept. The outstanding features of the modern economic system are overall, strategic, integral, and commanding. It not only contains the core elements of modern industrial system and economic modernization but also contains the content of institutional mechanisms and microfirm behavior.

For the interpretation of the connotation of the modern economic system, academic circles have expounded the connotation of building a modern economic system from different angles. Liu believed that the overall framework of the modern economic system is an innovation-driven, coordinated development industrial system, and the modern industrial system constitutes the material foundation that supports this system and framework [1]. Akulich and Kaźmierczyk believed that the main contradictions in the Chinese society have undergone profound changes. Based on the judgment of this change, our party has made important strategic deployments, that is, to implement new ideas and build a modern economic system, and explained the new thinking of China's economic development at multiple levels [2]. Gu believed that building an effective 
modern economic system and a coordinated industrial system can become the "two magic weapons" for highquality economic development and play a vital role in achieving sustainable economic growth [3]. He and Tang believed that the modern economic system is the modern system of advanced production methods, and the social production relationship is compatible with modern social productivity [4]. Cai dialectically grasped the scientific connotation of the modern economic system from the perspective of productivity and production relations and pointed out that the modern economic system is the unity of productivity and production relations when discussing the connotation of the modern economic system [5]. Zhao and Zhu understood the modern economic system from three aspects: first, the modern economic system is a modernization-oriented economic system; secondly, the modern economic system is an economic system that implements the new development concept; finally, the modern economic system realizes productivity and dynamic contact of production relations [6]. Zhang expounded the connotation of the modern economic system in the development of socialism with Chinese characteristics. The construction of a modern economic system is an urgent requirement for crossing the barrier and a strategic goal for China's development [7]. Liu pointed out that the basic feature of the modern economic system is the people-centered modern economic system, the main task is knowledge innovation, the important means is informatization, the industrial structure is constantly optimized, and urban and rural economy, regional economy, virtual economy, and real economy will develop in a more coordinated way [8]. Shi et al. understood the connotation of a modern economic system from three levels: at the microlevel, the basis of a modern economic system is the modernization of elements; at the mesolevel, the main goal of building a modern economic system is the modernization of the industrial system; at the macrolevel, the institutional guarantee for the construction of a modern economic system is the modernization of the economic system [9]. Foreign scholars are also studying the theory and connotation of the modern economic system: A analyzed the formation of a modern economic system, the formation of a production factor market, the development of a monetary and credit system, the formation of a sound industrial system and technical foundation, and the strengthening of the economy competitiveness [10]. Gashenko et al. proposed a theory and method to analyze the modern economic system, and this method can calculate the current level of innovation in the economic development system and provide the best model of innovation development in the modern economic system [11]. The research of Porket showed that the tension between economic individualism and economic collectives in a modern economic system will revolve around the role of the state in the global economy [12].

Due to different understandings of the definition of a modern economic system, many scholars have given different construction methods for the construction of a modern economic system. He and Shen demonstrated the positive effect of the improvement of the modern economic system on the improvement of total factor productivity and the quality of economic development from both theoretical and empirical perspectives on the basis of measuring the development degree of China's modern economic system by constructing evaluation indicators of the modern economic system [13]. Feng et al. proposed to realize the transformation from the first rich to the common prosperity in terms of development goals, in terms of development motivation, realize the replacement of low prices and high inputs with reform and opening up and technological innovation, and in terms of development quality, realize green development [14]. Rezai et al. analyzed the internal relationship between the income distribution structure and the construction of a modern economic system by analyzing the efficiency mechanism, fairness mechanism, and coordination mechanism, proceeded from the reality of China, and put forward policy recommendations for the construction of a modern economic system [15]. Gao and Cheng believe that China's modern economic system is based on the socialist market economic system and modern industrial system, driven by the progress of modern science and technology to realize the optimization of the industrial structure, the efficiency and efficiency of resource allocation, the continuous upgrading of product quality, as well as the implementation of new development concepts and sustainable development of the economic system [16]. Cheng and Chai proposed to adhere to the people-centered development approach to build a modern economic system, deepen supply-side structural reforms, implement a technological innovation-driven development strategy, strengthen the real economy, promote the coordinated development of urban and rural areas, and actively participate in the economy in the development strategy of globalization [17]. Li et al. evaluated and analyzed the construction of the modern economic system of the national resource-based economic transformation comprehensive reform zone in Shanxi Province by using the five evaluation indexes of the modern economic system, including the power system, the industrial system, the economic system, the opening up to the outside world, and the resource-based economic transformation [18]. Zhou used the evaluation indicators of economic strength, industrial structure, industrial system, innovation drive, factor input, demand structure, openness, urban and rural areas, resource environment, and economic system to evaluate the modern economic system of Guangzhou in the context of the Guangdong-Hong Kong Bay Area Construction of a modern economic system for evaluation and analysis [19]. Zhong evaluated and analyzed the regional modernized economic system of urban agglomerations from two perspectives: from the perspective of systems science, comprehensively evaluates and analyzes the construction of the modernized economic system of urban agglomerations from the perspective of industrial system, innovation system, urban system, market system, and supply system; from the angle of economics, this paper evaluates and analyzes the regional modern economic system of Changzhutan urban agglomeration from three aspects of economic strength, economic structure, and economic level [20]. Xie believed that, under the guidance of the new development concept of innovation, coordination, green development, openness, and sharing in 
the new era, China will build a modern economic system to promote the high-quality development of the Chinese economy [21]. Zhang and Liang evaluated and analyzed the construction of the modern economic system in 2020, 2035, and 2050 in stages from the first-level indicators such as the construction of supply and demand balance system, industrial system, market system, income system, and regional development system [22]. Liu evaluated and analyzed the construction level of the modern economic system in Hubei Province from seven first-level indicators: the overall level of economic development, the government's service ability to enterprises, innovation ability, the development level of modern industrial system, the degree of coordinated development between urban and rural areas, the level of open economy, and the development level of green economy [23].

Considering that the socialist modern economic system is a comprehensive system of economic construction, how to construct a modern economic system from the perspective of specific actions in this comprehensive system is a new and important issue worthy of consideration. Zou made a theoretical elaboration on the specific ideas of building a modernized economic system from five aspects, that is, insisting on innovation-driven development, improving total factor productivity, improving the quality of the supply system, establishing a new pattern of all-round opening up, and implementing the concept of green development to achieve higher-quality development [24]. Cai pointed out that, in order to better promote the rapid development of the modern economic system, it is necessary to combine the status quo of regional development and study the problems of the modern economic system from the perspective of regional economy [25]. Ren and Xing proposed the "124" breakthrough strategy on how to build a modern economic system in northern Anhui, that is, a main line of insisting on supply-side structural reforms, two strategic priorities for technological innovation and rural revitalization, and four strengthening organizational leadership, institutional supply, strategic guidance, and implementation measures of environmental governance [26]. Li put forward corresponding strategies for the innovation capabilities encountered in Shanghai's construction of a modern economic system, modern innovation system; industrial structure upgrading, open economy, and other issues, leading the financial system innovation and accelerating the construction of an international financial center [27]. Guha et al. used artificial intelligence to simplify the difficulties encountered in the study of the modern economic system and improved the accuracy of the study of the modern economic system by $17 \%$ [28]. Liu pointed out the problems of developing a modern economic system from eight aspects, including the industrial system, market system, distribution system, and regional development system, and proposed its solutions [29]. Knaus and Hund studied the impact of changes in traditional and modern economic systems on the values and family structure of Internet people and proposed that changes in the economic system could provide a deeper understanding of the mutual relationship between the family structure and value system [30].
It can be seen from the existing literature that most of the literature is studying the theory of the modern economic system and the index problem of constructing the modern economic system. This provides many innovative and useful ideas for studying the degree of perfection of the modern economic system, but it is urgently needed to be explored. One of the major problems in China is to transform the economic development mode, that is, to replace the traditional dependence on factor inputs to achieve economic development by increasing total factor productivity. Therefore, it is very important and urgent to study the total factor productivity and the modern economic system from the theoretical level or the practical level, but there are still few relevant studies.

The innovations' study in this article is as follows: first, on the basis of constructing the indicator system of the modern economic system, through theoretical and empirical analysis of how the modern economic system and total factor productivity promote high-quality economic development. The second is to use interprovincial panel data and introduce spatial correlation models to estimate the relationship between the modern economic system and total factor productivity, thus demonstrating that the construction of China's modern economic system must focus on improving total factor productivity. At present, no relevant scholars have conducted empirical research from this perspective, which is where the research value and innovation of this article lies.

\section{The Measurement of Total Factor Productivity and Its Temporal and Spatial Pattern}

2.1. Model Selection. Total factor productivity is an index used to measure efficiency. Except for the growth induced by factor inputs, the rest of the growth is derived from changes in productivity. The improvement of total factor productivity mainly comes from the improvement of efficiency, technological progress, and scale effect currently. The methods of total factor productivity measurement mainly include the parametric method and nonparametric method. The parametric method is represented by the Solow residual method and the stochastic frontier method; the nonparametric method mainly includes data envelopment analysis and DEA-Malmquist index method. This section selects and uses the widely used DEA-Malmquist productivity index model to measure China's total factor productivity from 2001 to 2017 in 30 provinces, municipalities, and autonomous regions. This model is chosen because the output distance function is defined according to the distance function, and the linear programming method is used to estimate the boundary production function of each DMU, and it can further analyze the technological progress and changes in technical efficiency and their impact on China's total factor productivity. The TFP change of total factor productivity in adjacent periods is expressed by the following formula: 


$$
M_{i}\left(x^{t+1}, y^{t+1}, x^{t}, y^{t}\right)=\left[\frac{D_{c i}^{t}\left(x^{t+1}, y^{t+1}\right)}{D_{c i}^{t}\left(x^{t}, y^{t}\right)} \times \frac{D_{c i}^{t+1}\left(x^{t+1}, y^{t+1}\right)}{D_{c i}^{t+1}\left(x^{t}, y^{t}\right)}\right]^{1 / 2}
$$

In formula (1), $x^{t}$ is the input variable of period $t, y^{t}$ is the output variable of period $t$, and $D_{c i}^{t}\left(x^{t}, y^{t}\right)$ and $D_{c i}^{t+1}\left(x^{t+1}, y^{t+1}\right)$ are the production frontiers of period $t$ and $t+1$, respectively. The next illustrates distance function value of the two periods; $D_{c i}^{t+1}\left(x^{t}, y^{t}\right)$ represents the distance function value of the $i$ th decision unit in the $t$ period under the production frontier of period $t+1 ; D_{c i}^{t}\left(x^{t+1}, y^{t+1}\right)$ represents the distance function value of the $i$ th decision unit in the production frontier of period $t$, which is the distance function value of period $t+1 ; M_{i}\left(x^{t+1}, y^{t+1}, x^{t}, y^{t}\right)$ is the change of TFP, and this value is equal to 1 means the value of TFP remains unchanged, lower than 1 means TFP decreases, and greater than 1 means TFP increases.

Through the decomposition of $M_{i}\left(x^{t+1}, y^{t+1}, x^{t}, y^{t}\right)$, the efficiency and technical changes can be measured, as shown in the following formula:

$$
M_{i}\left(x^{t+1}, y^{t+1}, x^{t}, y^{t}\right)=T E c h_{i}^{t+1} \times T P E c h_{i}^{t+1}=\frac{D_{c i}^{t+1}\left(x^{t+1}, y^{t+1}\right)}{D_{c i}^{t}\left(x^{t}, y^{t}\right)} \times\left[\frac{D_{c i}^{t}\left(x^{t}, y^{t}\right)}{D_{c i}^{t+1}\left(x^{t}, y^{t}\right)} \times \frac{D_{c i}^{t}\left(x^{t+1}, y^{t+1}\right)}{D_{c i}^{t+1}\left(x^{t+1}, y^{t+1}\right)}\right]^{1 / 2} .
$$

In formula (2), the first part of the technical efficiency change $T E c h_{i}^{t+1}$ represents the utilization status of the technology, that is, whether the output of the decisionmaking unit $i$ has reached the expected effect under a given input; the second part of the technical progress rate change
$T P E c h_{i}^{t+1}$ represents the technological progress of the decision-making unit $i$ happening.

The further decomposition process of changes in technical efficiency (TEch) is shown in the following formula:

$$
T E c h=P T E c h \times S E c h=\frac{D_{v i}^{t+1}\left(x^{t+1}, y^{t+1}\right)}{D_{v i}^{t}\left(x^{t}, y^{t}\right)} \times\left[\frac{D_{v i}^{t}\left(x^{t}, y^{t}\right)}{D_{c i}^{t+1}\left(x^{t}, y^{t}\right)} / \frac{D_{v i}^{t}\left(x^{t+1}, y^{t+1}\right)}{D_{c i}^{t+1}\left(x^{t+1}, y^{t+1}\right)}\right]^{1 / 2} .
$$

In formula (3), TEch is the pure technical efficiency change, $S E c h$ is the scale efficiency change, and $D_{v}(x, y)$ and $D_{c}(x, y)$ are the distance functions with variable and constant returns to scale, respectively. For the $i$ th decisionmaking unit, the above four TFP decomposition index values are less than 1 , which means that it has a hindering effect on TFP and vice versa.

2.2. Empirical Results. Drawing on previous research results, the output indicator is expressed by the GDP of each province, the capital input indicator is expressed by the total social fixed asset investment of each province, and the labor input indicator is expressed by the number of employees at the end of the year. The GDP deflator and fixed asset price index of each province were used to deflate the regional GDP and fixed asset investment. After calculation, the national average total factor productivity index and its decomposition from 2001 to 2017 are shown in Table 1.

According to Table 1 and Figure 1, during the 17 years of the estimation period, the fluctuation trend of China's total factor productivity generally showed four troughs and three crests, forming four "decline-up" cycles. The first cycle lasted from 2001 to 2004 and lasted for 4 years. During this period, the total factor productivity dropped by $0.08 \%$ on average; the second cycle was from 2004 to 2007 and lasted for 4 years. During this period, the total factor productivity was 4 years.
Productivity increased by an average of $0.06 \%$; the third cycle was formed during the five years from 2007 to 2011, during which total factor productivity fell by an average of $0.27 \%$; the fourth cycle was formed during the seven years from 2011 to 2017, during which the entire period factor productivity dropped by $0.26 \%$ on average.

In addition to the increase of $0.23 \%$ in the rate of technological progress during the estimation period, the technical efficiency, pure technical efficiency, and scale efficiency all declined during the estimation period with a decrease of $0.40 \%, 0.26 \%$, and $0.14 \%$, respectively. The reduction of technical efficiency and scale efficiency hinders the improvement of China's total factor productivity. By analyzing the national average total factor productivity index and its decomposition results from 2001 to 2017, it can be concluded that the overall level of China's total factor productivity is not high and its growth is relatively slow from the time dimension. The key to improve the modern economic system is to revitalize the total factor productivity and then use the Malmquist Productivity Index to conduct a centralized analysis at the provincial level. Table 2 shows the national cumulative Malmquist productivity index and its decomposition from 2001 to 2017.

It can be seen from Table 2 and Figure 2 that, except for the four provinces of Shanxi, Guangxi, Chongqing, and Yunnan, the average total factor productivity index of China in the past 17 years was above 0.7 but not more than 0.8 . In 
TABLE 1: 2001-2017 national average total factor productivity index and its decomposition.

\begin{tabular}{|c|c|c|c|c|c|}
\hline Year & $\begin{array}{l}\text { Technical efficiency } \\
\text { change index }\end{array}$ & $\begin{array}{c}\text { Technological } \\
\text { progress } \\
\text { rate change index }\end{array}$ & $\begin{array}{l}\text { Pure technical efficiency } \\
\text { change index }\end{array}$ & $\begin{array}{c}\text { Scale } \\
\text { efficiency change } \\
\text { index }\end{array}$ & $\begin{array}{l}\text { Total factor productivity } \\
\text { (TFP) }\end{array}$ \\
\hline 2001 & 0.806 & 0.886 & 0.895 & 0.901 & 0.714 \\
\hline 2002 & 0.781 & 0.908 & 0.882 & 0.885 & 0.709 \\
\hline 2003 & 0.773 & 0.917 & 0.872 & 0.886 & 0.708 \\
\hline 2004 & 0.766 & 0.931 & 0.873 & 0.877 & 0.713 \\
\hline 2005 & 0.779 & 0.905 & 0.887 & 0.878 & 0.705 \\
\hline 2006 & 0.773 & 0.912 & 0.877 & 0.881 & 0.705 \\
\hline 2007 & 0.777 & 0.919 & 0.881 & 0.882 & 0.714 \\
\hline 2008 & 0.785 & 0.909 & 0.889 & 0.883 & 0.714 \\
\hline 2009 & 0.795 & 0.871 & 0.897 & 0.886 & 0.692 \\
\hline 2010 & 0.777 & 0.901 & 0.883 & 0.880 & 0.700 \\
\hline 2011 & 0.789 & 0.895 & 0.891 & 0.886 & 0.707 \\
\hline 2012 & 0.789 & 0.883 & 0.888 & 0.888 & 0.696 \\
\hline 2013 & 0.780 & 0.883 & 0.877 & 0.889 & 0.688 \\
\hline 2014 & 0.781 & 0.871 & 0.883 & 0.884 & 0.680 \\
\hline 2015 & 0.773 & 0.887 & 0.875 & 0.883 & 0.685 \\
\hline 2016 & 0.765 & 0.903 & 0.867 & 0.882 & 0.691 \\
\hline 2017 & 0.757 & 0.919 & 0.859 & 0.881 & 0.695 \\
\hline Mean & 0.779 & 0.900 & 0.881 & 0.884 & 0.701 \\
\hline
\end{tabular}

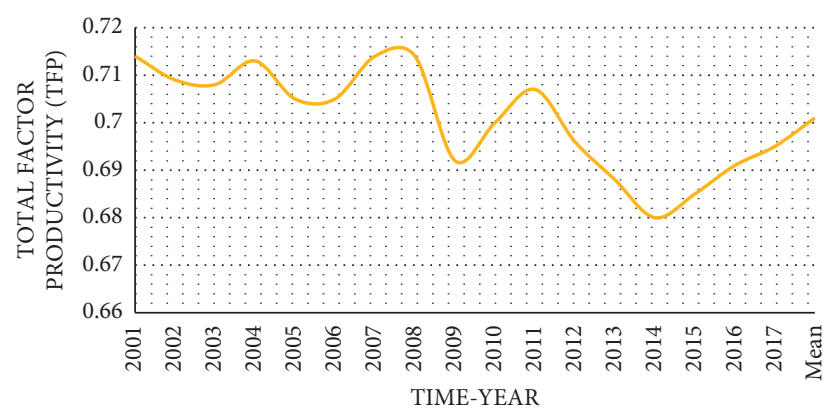

FIGURE 1: 2001-2017 national average total factor productivity trend.

general, the change in total factor productivity is measured by 1 . During the sample period, the total factor productivity of most provinces in China showed an irregular declining trend, and only a few provinces experienced slower growth in total factor productivity. During the period from 2001 to 2017, the average total factor productivity of East China, South China, North China, and Northeast China was above 0.7 , and the average total factor productivity of Central, Northwest, and Southwest China was around 0.6. From a spatial perspective, the regional gap in China's total factor productivity is obvious.

By measuring and decomposing total factor productivity and analyzing its temporal and spatial characteristics, it is found that the total factor productivity fluctuates around 0.7 from the time dimension, and the fluctuation range is not large; from the spatial perspective, the regional gap is large, and the rate of technological progress is relatively large. With the increase in total factor productivity, it also shows an upward trend, which indicates that the increase in the rate of technological progress is the main driving force for the growth of total factor productivity.

\section{Evaluation of the Degree of Perfection of the Modern Economic System}

The connotation of the modern economic system can be divided into four points: first, China's modern economic system is an economic system that is deeply integrated with information; second, China's modern economic system is an intensive and connotative development innovation-driven system; Once again, China's modern economic system is an economic system that attaches great importance to ecological civilization and green development. The basic requirement of sustainable development is to take less environmental pollution and low resource consumption as the primary goals, so as to achieve sustained, stable, and healthy economic development; finally, China's modern economic system is an economic system that seeks happiness for the people and gives full play to the advantages of human resources [31]. By understanding the connotation of the modern economic system, this article builds on the basis of previous research and the actual situation of China's own development to construct an indicator system from the five 
TABLE 2: 2001-2017 national cumulative total factor productivity index and its decomposition.

\begin{tabular}{|c|c|c|c|c|c|}
\hline Region & $\begin{array}{c}\text { Technical efficiency } \\
\text { change index }\end{array}$ & $\begin{array}{c}\text { Technological progress rate } \\
\text { change index }\end{array}$ & $\begin{array}{l}\text { Pure technical efficiency } \\
\text { change index }\end{array}$ & $\begin{array}{c}\text { Scale } \\
\text { efficiency change index }\end{array}$ & $\begin{array}{c}\text { Total factor } \\
\text { productivity (TFP) }\end{array}$ \\
\hline Beijing & 0.790 & 0.938 & 0.882 & 0.896 & 0.741 \\
\hline Tianjin & 0.803 & 0.930 & 0.900 & 0.892 & 0.747 \\
\hline Hebei & 0.789 & 0.890 & 0.883 & 0.893 & 0.702 \\
\hline Shanxi & 0.786 & 0.889 & 0.880 & 0.893 & 0.699 \\
\hline Neimenggu & 0.773 & 0.920 & 0.865 & 0.894 & 0.711 \\
\hline Liaoning & 0.791 & 0.920 & 0.888 & 0.891 & 0.728 \\
\hline Jiling & 0.771 & 0.911 & 0.862 & 0.895 & 0.703 \\
\hline Heiongjiang & 0.804 & 0.898 & 0.900 & 0.893 & 0.722 \\
\hline Shanghai & 0.798 & 0.945 & 0.894 & 0.893 & 0.754 \\
\hline Jiangsu & 0.805 & 0.911 & 0.904 & 0.890 & 0.733 \\
\hline Zhejiang & 0.799 & 0.916 & 0.895 & 0.893 & 0.732 \\
\hline Anhui & 0.799 & 0.886 & 0.893 & 0.895 & 0.708 \\
\hline Fujian & 0.786 & 0.906 & 0.879 & 0.894 & 0.712 \\
\hline Jiangxi & 0.802 & 0.887 & 0.899 & 0.892 & 0.711 \\
\hline Shandong & 0.796 & 0.892 & 0.892 & 0.892 & 0.710 \\
\hline Henan & 0.806 & 0.870 & 0.870 & 0.926 & 0.701 \\
\hline Hubei & 0.799 & 0.871 & 0.894 & 0.894 & 0.696 \\
\hline Hunan & 0.799 & 0.870 & 0.892 & 0.896 & 0.695 \\
\hline Guangdong & 0.797 & 0.904 & 0.893 & 0.893 & 0.721 \\
\hline Guangxi & 0.768 & 0.886 & 0.859 & 0.894 & 0.680 \\
\hline Hainan & 0.805 & 0.890 & 0.903 & 0.891 & 0.716 \\
\hline Chongqin & 0.789 & 0.852 & 0.885 & 0.891 & 0.672 \\
\hline Sichuan & 0.805 & 0.852 & 0.898 & 0.896 & 0.686 \\
\hline Guizhou & 0.793 & 0.852 & 0.891 & 0.890 & 0.676 \\
\hline Yunnan & 0.787 & 0.853 & 0.881 & 0.893 & 0.671 \\
\hline Shanxi & 0.802 & 0.840 & 0.899 & 0.892 & 0.674 \\
\hline Gansu & 0.794 & 0.835 & 0.893 & 0.889 & 0.663 \\
\hline Qinghai & 0.788 & 0.844 & 0.901 & 0.875 & 0.665 \\
\hline Ningxia & 0.776 & 0.858 & 0.887 & 0.875 & 0.666 \\
\hline Xinjiang & 0.792 & 0.868 & 0.886 & 0.894 & 0.688 \\
\hline Huadong & 0.798 & 0.906 & 0.894 & 0.893 & 0.723 \\
\hline Huanan & 0.790 & 0.893 & 0.885 & 0.893 & 0.706 \\
\hline Huazhong & 0.801 & 0.870 & 0.885 & 0.905 & 0.697 \\
\hline Huabei & 0.788 & 0.913 & 0.882 & 0.894 & 0.720 \\
\hline Xibei & 0.790 & 0.849 & 0.893 & 0.885 & 0.671 \\
\hline Xinan & 0.793 & 0.852 & 0.889 & 0.893 & 0.676 \\
\hline Dongbei & 0.789 & 0.910 & 0.883 & 0.893 & 0.717 \\
\hline
\end{tabular}

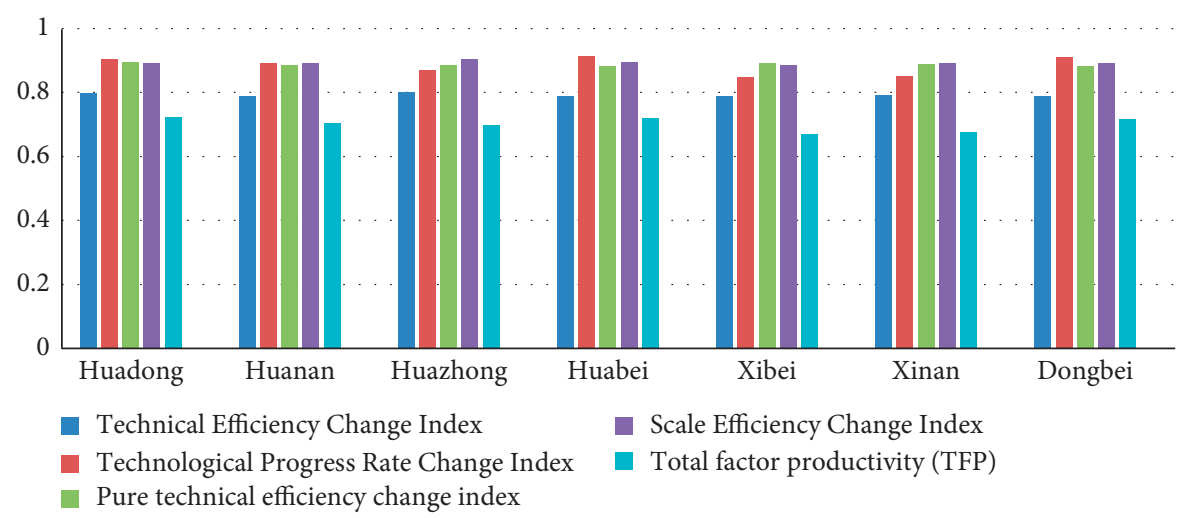

FIgURE 2: 2001-2017 national total factor productivity trends by region.

dimensions of scale, structure, quality, technology, and environmental protection to measure the performance of China's modern economic system. The construction status and development level are shown in Table 3 below.
3.1. Evaluation Method. This study also adopted the method of nondimensional processing of the original indicators using the method of averaging to solve the problem of different measurement units and orders of magnitude of 
TABLE 3: Comprehensive evaluation index system of the modern economic system.

\begin{tabular}{lcc}
\hline Classification framework & Basic indicators & Calculation formula \\
\hline $\begin{array}{l}\text { The scale of the modern economic } \\
\text { system }\end{array}$ & Ratio of total industrial output & $\begin{array}{c}\text { Gross industrial output value/gross domestic product (\%) } \\
\text { Regional urban permanent population/regional total } \\
\text { permanent population (\%) }\end{array}$ \\
\hline
\end{tabular}

Contribution of the tertiary industry

Tertiary industry output value/gross domestic product

The structure of the modern economic system
Employment ratio of tertiary industry

Proportion of high-tech industry output High-tech industry output value/gross industrial output value

Overall labor productivity GDP per capita

Per capita income of residents

The qualitem
system

Research and development $(\mathrm{R} \& \mathrm{D})$

personnel

The innovation drive of a modern economic system

Research and development (R\&D)

expenses

Licensing

Employment in the tertiary industry/total number of employees in the whole society (\%) value $(\%)$

Industrial added value/average number of employees (\%) GDP per capita (yuan) Per capita income of residents (yuan)

Research and development (R\&D) personnel (people)

Research and development $(\mathrm{R} \& \mathrm{D})$ expenditure (ten thousand yuan)

Number of patent applications (A)

Green development status of

Energy consumption per unit of GDP carbon dioxide emissions
Energy consumption per unit of GDP total (\%) carbon dioxide emissions (ten thousand tons) different indicators in the comprehensive evaluation indicator system of the modern economic system mentioned above. Principal component analysis is a multivariate statistical method in which multiple variables are linearly transformed to select a small number of important variables. The comprehensive principal component analysis can get the comprehensive evaluation model of each province. The specific steps and formulas (4) and (5) are as follows:

(1) Nondimensional quantification of the original data

(2) Calculate the sample correlation matrix $R$ :

$$
R=\left(r_{i j}\right)_{P \times P}=X^{\prime} X,
$$

$r_{i j}$ is a simple coefficient of index $i$ and index $j$

(3) Calculate the eigenvalue $\lambda_{i}$ and unit eigenvector $\gamma_{p}$ of the correlation matrix $R$

(4) Calculate the eigenvalue contribution rate and cumulative contribution rate $\mu=\sum_{i=1}^{m} \lambda_{i} /\left(\sum_{i=1}^{p} \lambda_{i}\right)$

In practical applications, $m$ principal components are generally selected, $m<p$, and the cumulative contribution rate reaches $85 \%$ or more. And, write the principal components:

$$
F_{m}=u_{m 1} x_{1}+u_{m 2} x_{2}+\cdots+u_{m p} x_{p}
$$

The following of the paper provides an economic explanation of the selected principal components based on the calculation results of the principal components combined with qualitative analysis.

3.2. Evaluation Results and Analysis. The factor analysis of the dominant index (SPSS20.0 software) shows that the cumulative variance contribution rate of the three extracted factors has reached $85.29 \%$, that is, the three extracted factors can basically cover all the original data information. Then, by weighting the index values of China's 30 provinces according to the weight of the evaluation index obtained, the comprehensive evaluation score of the perfection of China's modern economic system is finally calculated. Table 4 below is the average value of the comprehensive scores of modernized economic systems in various regions of China.

Analyze the results in Table 4: from an overall point of view, the national average of the comprehensive score of China's modern economic system is 0.536 , and only the top ten provinces have a comprehensive score of the modern economic system that exceeds the national average score, which shows that the overall level of China's modern economic system is low, and the construction of a modern economic system is still in its infancy. From a regional perspective, the comprehensive score of China's modern economic system shows a gradual trend from west to east. Eastern China has the highest comprehensive score of the modern economic system, reaching 0.912 , followed by North China, which ranks second in comprehensive score, reaching 0.597 above the national average, followed by South China, with a comprehensive score of 0.580 . It is also above the national average, ranking third, and the northeast region is fourth, with a comprehensive score of 0.4131 . Finally, the southwest and northwest regions have a comprehensive score below 0.4 , which is a clear gap with the eastern region.

It can be seen from this that the construction and improvement of China's modern economic system have obvious characteristics of regional imbalance, and speeding up the construction of a modern economic system in the central and western regions is an important issue that cannot be ignored.

\section{Research on the Impact of Total Factor Productivity on the Improvement of the Modern Economic System}

China's modern economic system is not yet sound. The root cause is the long-term downturn in total factor productivity. What is the impact of total factor 
TABle 4: Average comprehensive scores of modernized economic systems in various regions.

\begin{tabular}{|c|c|c|c|c|c|}
\hline Province & Score & Rank & Province & Score & Rank \\
\hline Shanghai & 1.325 & 1 & Hebei & 0.365 & 20 \\
\hline Guangdong & 1.118 & 2 & Jilin & 0.354 & 21 \\
\hline Beijing & 1.102 & 3 & Guizhou & 0.339 & 22 \\
\hline Jiangsu & 1.005 & 4 & Sichuan & 0.327 & 23 \\
\hline Zhejiang & 0.992 & 5 & Ningxia & 0.306 & 24 \\
\hline Tianjin & 0.876 & 6 & Gansu & 0.302 & 25 \\
\hline Shandong & 0.737 & 7 & Qinghai & 0.289 & 26 \\
\hline Fujian & 0.601 & 8 & Neimeng & 0.242 & 27 \\
\hline Hubei & 0.557 & 9 & Yunnan & 0.225 & 28 \\
\hline Hunan & 0.551 & 10 & Guangxi & 0.224 & 29 \\
\hline Shanxi & 0.527 & 11 & Xijiang & 0.168 & 30 \\
\hline Chongqin & 0.514 & 12 & Huadong & 0.912 & - \\
\hline Anhui & 0.503 & 13 & Huabei & 0.597 & - \\
\hline Liaoning & 0.478 & 14 & Huanan & 0.580 & - \\
\hline Henan & 0.459 & 15 & Huazhong & 0.498 & - \\
\hline Jiangxi & 0.423 & 16 & Dongbei & 0.413 & - \\
\hline Helongjiang & 0.408 & 17 & Xinan & 0.351 & - \\
\hline Shanxi & 0.399 & 18 & Xibei & 0.318 & - \\
\hline Hainan & 0.378 & 19 & Quanguo & 0.536 & - \\
\hline
\end{tabular}

productivity on the improvement of the modern economic system? In order to solve this problem, this section first describes the relationship between the modern economic system and total factor productivity and then studies the influence of total factor productivity on the modern economic system by using the traditional static spatial econometric model and the dynamic spatial panel regression model which can investigate the dynamic characteristics.

\subsection{The Mechanism of Total Factor Productivity on the Modern} Economic System. Total factor productivity is not only the core of high-quality economic development but also a core indicator for measuring the quality of economic development. According to the connotation of the modern economic system, the mechanism of action between total factor productivity and the modern economic system can be explained from the following aspects: firstly, the key to the improvement of total factor productivity is technological innovation. Technological innovation will bring about technological progress and efficiency improvement, and innovation strategy is the strategic support for the construction of a modern economic system, so technological innovation will increase total factor productivity and improve the modern economy system. Secondly, system optimization can eliminate some institutional factors that originally inhibited the production efficiency of enterprises, and enterprises can maximize efficiency, thereby increasing total factor productivity. In the improvement of the modern economic system, market structural reforms are also the key in a sexual step, and the optimization of the market system can increase the total factor productivity and make the modern economic system more complete. Thirdly, a modern supply system is the key to improving total factor productivity. Increasing total factor productivity can increase the efficiency of product production and service, which is conducive to the construction of a modern economic system; the fourth is an open economic environment, and China has closer ties with other countries. Frequent flow of production factors can reduce production costs, thereby increasing total factor productivity and being conducive to the construction of a modern economic system. For China's economy to have high-quality development, speeding up the construction and improvement of a modern economic system and increasing total factor productivity are the main tasks facing China.

4.2. Model Setting. Since the value of the total factor productivity calculated by the above model is greater than 0 , it is a restricted variable; directly use this value as the explained variable to establish a measurement model, and use ordinary least squares to regress the model. In order to analyze the impact of total factor productivity on the degree of perfection of the modern economic system, this article intends to establish the following model:

$$
\mathrm{MES}_{i t}=\alpha_{0}+\tau_{i t} \mathrm{TFP}+\alpha C_{i t}+\mu_{i t} .
$$

In formula (6), $i$ represents the domestic provinces, $t$ represents the year, MES represents the degree of perfection of the modern economic system, $\alpha_{0}$ is a constant term, TFP is the core explanatory variable total factor productivity, $\tau$ is the regression coefficient of the core explanatory variable, $C$ is the control variable, $\alpha$ is the regression coefficient of the control variable, and $\mu$ is the random error term.

4.3. Selection of Variables and Data. This article draws on the research of related scholars and also selects four control variables, industrial structure upgrade, factor marketization degree, environmental governance intensity, and degree of opening to the outside world, to study its influence on the degree of perfection of the modern economic system. The relevant original data in this article comes from the "China Statistical Yearbook," "China Labor Statistics Yearbook," "China Industrial Statistics Yearbook," "China Science and 
Technology Statistical Yearbook," and statistical yearbooks and bulletins of various provinces over the years. (1) Industrial structure upgrade (ST): an important aspect of constructing China's modern economic system is to accelerate the transformation and upgrading of China's industrial structure. The industrial structure upgrade coefficient of this study adopts the method of Gan et al. [32] and selects the ratio of the output value of the tertiary industry to the output value of the secondary industry to calculate. (2) The degree of factor marketization (MR): another key problem in building a modern economic system is to promote the marketization of factors and improve the utilization efficiency of factors in different industries and regions. The development of the factor market is still the shortcoming of China's marketization. The method for measuring the degree of factor marketization in this study draws on the practice of Lei [33] and uses the ratio of the added value of state-owned large-scale industrial enterprises to the added value of large-scale industrial enterprises. (3) Environmental governance intensity (IM): the construction of a modern economic system must also vigorously implement the concept of green development. At this stage, China still continues to develop a mode of high-energy consumption and high investment. The tightening of resource and environmental constraints and ecological environmental issues are the shortcomings of the decisive stage of building a well-off society in an all-round way. It is imperative for the economy to develop towards an environment-friendly and resource-intensive type. This study uses the proportion of environmental pollution control investment in GDP to measure the intensity of environmental governance. (4) The degree of opening to the outside world (OP): practice has proved that China's economic development has been achieved under the conditions of reform and opening up. The construction of China's modern economic system and the realization of high-quality economic development in China must also be carried out under more open conditions. This study uses the proportion of total imports and exports to GDP to represent external openness.

\subsection{Estimation Results and Analysis}

4.4.1. Spatial Correlation Test. According to the theory of new economic geography, even today with the continuous advancement of economic globalization and regional integration, spatial distance still has an important impact on the economic relationship between regions. In order to avoid possible estimation biases that do not consider spatial correlation, we need to introduce a model that considers spatial correlation to estimate the relationship between the modern economic system and total factor productivity. According to the spatial correlation theory, global spatial Moran's I index method must be used to determine whether the variables have spatial correlation before establishing the spatial measurement model. The formula for calculating the Moran index is as follows:

$$
\text { Moran's } I=\frac{\sum_{i=1}^{n} \sum_{j=1}^{n} W_{i j}\left(Y_{i}-\bar{Y}\right)\left(Y_{j}-\bar{Y}\right)}{S^{2} \sum_{i=1}^{n} \sum_{j=1}^{n} W_{i j}} .
$$

In formula (7), $S^{2}=(1 / n) \sum_{i=1}^{n}\left(Y_{i}-\bar{Y}\right)^{2}, \bar{Y}=(1 / n) \sum_{i=1}^{n}$ $Y_{i}, i$ are regional observations, $n$ is the total number of regions, and $W_{i j}$ is the spatial weight matrix. The article uses the reciprocal of the distance as the distance function, and the geographic distance is used to set the spatial weight matrix. The results of calculated global space Moran's I index are shown in Table 5.

Table 5 and Figure 3 show the test results of the spatial correlation between the degree of perfection of China's modern economic system and total factor productivity from 2001 to 2017. The results show that Moran's I index of modern economic system perfection and total factor productivity both pass the test at a significant level of 5\%, indicating that the perfection of the modern economic system and total factor productivity are spatially correlated, and spatial econometric analysis methods are suitable.

4.4.2. Space Panel Model Setting. Considering the robustness of the test results, the article adopts two different spatial weight matrices and successively conducts the regression test of the spatial lag SAR model, the spatial error SEM model, and the spatial Dubin SDM model. Construct the first spatial weight matrix $W_{1}$ based on the geographic distance, that is, the reciprocal of the distance as the distance function, and use the binary assignment method of 0 and 1 , that is, the adjacent provinces are 1 , and the nonadjacent provinces and themselves are $0 . W_{2}$ is the second spatial weight matrix. The model settings all use the indicator of the perfection of the modern economic system as the explanatory variable, the total factor productivity as the explanatory variable, and the four indicators of industrial structure upgrade, factor marketization, environmental governance intensity, and openness as the control variables. The specific model settings are as follows as equations (8)-(11):

Space lagging SAR model:

$$
M E S_{i t}=\rho \sum_{j=1}^{N} W_{i j} M E S_{j t}+\alpha_{1} T F P_{i t}+\alpha_{2} S T_{i t}+\alpha_{3} M R_{i t}+\alpha_{4} I M_{i t}+\alpha_{5} O P+\varepsilon_{i t} .
$$

Spatial error SEM model: 
TABLE 5: 2007-2017 Moran index of total factor productivity and the perfection of the modern economic system.

\begin{tabular}{|c|c|c|c|c|}
\hline \multirow[t]{2}{*}{ Year } & \multicolumn{2}{|c|}{ TFP } & \multicolumn{2}{|c|}{$\begin{array}{l}\text { The degree of perfection of the modern } \\
\text { economic system }\end{array}$} \\
\hline & Moran's I & $P$ value & Moran's I & $P$ value \\
\hline 2001 & 0.016 & 0.004 & 0.278 & $\leq 0.001$ \\
\hline 2002 & 0.070 & 0.010 & 0.418 & $\leq 0.001$ \\
\hline 2003 & 0.062 & $\leq 0.001$ & 0.422 & $\leq 0.001$ \\
\hline 2004 & 0.015 & $\leq 0.001$ & 0.531 & $\leq 0.001$ \\
\hline 2005 & 0.082 & $\leq 0.001$ & 0.787 & $\leq 0.001$ \\
\hline 2006 & 0.097 & $\leq 0.001$ & 0.612 & $\leq 0.001$ \\
\hline 2007 & 0.116 & 0.037 & 0.478 & 0.005 \\
\hline 2008 & 0.170 & $\leq 0.001$ & 0.568 & $\leq 0.001$ \\
\hline 2009 & 0.153 & $\leq 0.001$ & 0.420 & 0.011 \\
\hline 2010 & 0.115 & 0.032 & 0.631 & 0.020 \\
\hline 2011 & 0.015 & 0.001 & 0.587 & $\leq 0.001$ \\
\hline 2012 & 0.037 & 0.016 & 0.416 & $\leq 0.001$ \\
\hline 2013 & 0.082 & 0.020 & 0.470 & 0.033 \\
\hline 2014 & 0.068 & 0.032 & 0.562 & $\leq 0.001$ \\
\hline 2015 & 0.050 & 0.005 & 0.415 & $\leq 0.001$ \\
\hline 2016 & 0.060 & $\leq 0.001$ & 0.582 & 0.001 \\
\hline 2017 & 0.066 & $\leq 0.001$ & 0.416 & 0.012 \\
\hline
\end{tabular}

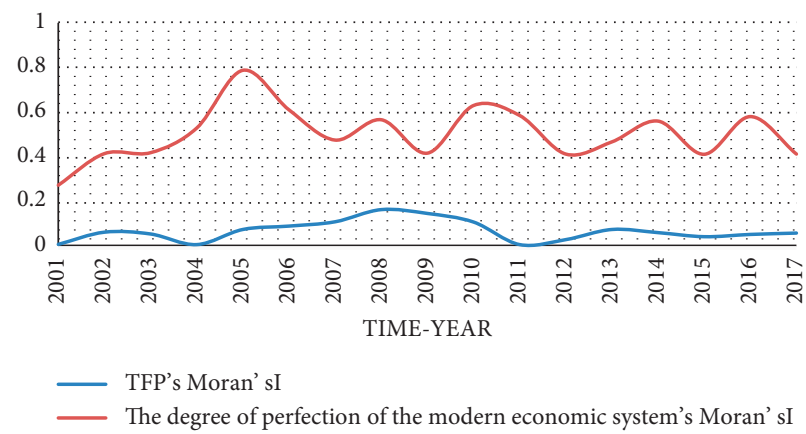

Figure 3: 2007-2017 Moran index of total factor productivity and modern economic system.

$$
\begin{aligned}
M E S_{i t}= & \alpha_{1} T F P_{i t}+\alpha_{2} S T_{i t}+\alpha_{3} M R_{i t} \\
& +\alpha_{4} I M_{i t}+\alpha_{5} O P+\mu_{i}+\varphi_{i t}, \\
\varphi_{i t}= & \lambda \sum_{j=1}^{N} W_{i j} \varphi_{i t}+\varepsilon_{i t} .
\end{aligned}
$$

Space Dubin SDM model:

$$
\begin{aligned}
M E S_{i t}= & \rho \sum_{j=1}^{N} W_{i j} M E S_{j t}+\alpha_{1} T_{F P_{i t}}+\alpha_{2} S T_{i t}+\alpha_{3} M R_{i t}+\alpha_{4} I M_{i t}+\alpha_{5} O P \\
& +\rho \sum_{j=1}^{N} W_{i j}\left(\beta_{1} T F P_{i t}+\beta_{2} H C_{i t}+\beta_{3} P S_{i t}+\beta_{4} I N_{i t}+\beta_{5} O P\right)+\varepsilon_{i t} .
\end{aligned}
$$

4.4.3. Regression Results of Spatial Correlation. Based on the traditional static spatial econometric model, the dynamic spatial panel regression model is used to investigate the dynamic characteristics, and then, the two-step system GMM estimation is further used to reduce the error effect caused by the endogeneity problem. The dynamic panel regression examines the first-order lagging dependent variable in order to minimize the degree of freedom and reduce the mutual interference of space lag and time lag. The estimation results of the spatial measurement model are shown in Table 6 . 
TABLE 6: Estimated results of the spatial measurement model.

\begin{tabular}{|c|c|c|c|c|c|c|}
\hline \multirow{2}{*}{$\begin{array}{l}\text { Model category } \\
\text { Spatial weight }\end{array}$} & \multirow{2}{*}{$\begin{array}{c}\text { Model } 1 \text { SAR_FE } \\
W_{1}\end{array}$} & \multirow{2}{*}{$\begin{array}{c}\text { Model } 2 \text { SDM_fe } \\
W_{1}\end{array}$} & \multicolumn{2}{|c|}{ Model 3 SAR_GMM } & \multicolumn{2}{|c|}{ Model 4 SDM_GMM } \\
\hline & & & $W_{1}$ & $W_{2}$ & $W_{1}$ & $W_{2}$ \\
\hline TFP & $0.6101^{* *}(6.04)$ & $0.5907^{* *}(4.59)$ & $0.3129^{* *}(2.85)$ & $0.5181^{*}(4.90)$ & $0.4215^{* *}(3.34)$ & $0.5523^{*}(4.14)$ \\
\hline ST & $0.3332 *(1.20)$ & $0.4138^{*}(2.35)$ & $0.4007^{* *}(1.32)$ & $0.5011^{* *}(3.42)$ & $0.4140 * *(2.13)$ & $0.5042^{* *}(3.58)$ \\
\hline MR & $0.5612(3.85)$ & $0.6810(3.47)$ & $0.6272(3.30)$ & $0.5346(2.47)$ & $0.6179(3.11)$ & $0.5261(2.35)$ \\
\hline IM & $0.0147^{*}(0.39)$ & $0.0175^{* *}(0.56)$ & $0.0183^{* *}(0.61)$ & $0.0124^{* *}(0.38)$ & $0.0076^{* *}(0.13)$ & $0.0115^{* *}(0.23)$ \\
\hline OP & $0.0249 *(0.41)$ & $0.0302 *(1.12)$ & $0.1228^{* *}(2.34)$ & $0.0387^{* *}(0.64)$ & $0.0338^{* * *}(0.53)$ & $0.0211^{* * *}(0.39)$ \\
\hline $\mathrm{W}^{*} \mathrm{TFP}$ & - & $0.0263^{* * *}(1.56)$ & - & - & $0.0741^{*}(2.24)$ & $0.0324^{*}(1.74)$ \\
\hline $\mathrm{W}^{*} \mathrm{MES}$ & $0.654^{* * *}(4.17)$ & $0.7447^{* * *}(6.89)$ & $0.1048^{* *}(0.52)$ & $0.1206^{* *}(0.68)$ & $0.1014^{* * *}(0.57)$ & $0.2018^{* * *}(0.76)$ \\
\hline L.MES & - & - & $0.6127^{* * *}(11.88)$ & $0.4377^{* * *}(8.79)$ & $0.7565^{* *}(12.03)$ & $0.8235^{* *}(14.67)$ \\
\hline$R^{2}$ & 0.7235 & 0.8718 & 0.7972 & 0.7798 & 0.8807 & 0.9028 \\
\hline IMSAR (robust) & $76.32^{* * *}$ & Wald: & - & - & - & - \\
\hline LMSAR (robust) & $134.61^{* * *}$ & $97.81^{* *}$ & Sargan: & Sargan: & Sargan: & Sargan: \\
\hline LMSEM (robust) & $\begin{array}{l}58.73^{* * *} \\
75.14^{* * *}\end{array}$ & $\begin{array}{c}\text { LR } \\
94.28^{* * *}\end{array}$ & 22.31 & 28.22 & 27.17 & 25.42 \\
\hline
\end{tabular}

***, ${ }^{* *}$, and ${ }^{*}$ indicate significant at the $1 \%, 5 \%$, and $10 \%$ levels, respectively.

At the same time, multiple models were used for regression testing and comparative analysis, and a more comprehensive quantitative study was conducted on the relationship between the perfection of the modern economic system and total factor productivity. The results in Table 6 will be analyzed and discussed below. Model 1-Model 4 represent the spatial lagging SAR model, the spatial Dubin SDM model, the dynamic spatial lag SAR_GMM model, and the dynamic spatial Dubin SDM_GMM model, respectively.

According to the results in Table 6, firstly, by comparing the test statistics of LMsem and robust LMsem with those of LMsar and robust LMsar, it can be seen that choosing a spatial panel lagging SAR model is more reasonable than choosing a spatial panel error SEM model. By analyzing the estimation results of Wald test and LR test, it is found that the null hypothesis of rejecting the Doberman spatial panel regression model is rejected, that is, the spatial Doberman SDM regression model should be selected in the end. In view of the fact that the geographical distance weight matrix $W_{1}$ can take into account the spatial weight of nonadjacent regions and can more accurately reflect the characteristics of spatial correlation, this article mainly focuses on the estimation results of the geographical distance weight matrix $W_{1}$. The analysis of the results of this study is mainly based on the spatial Doberman model, combined with the estimation results of the dynamic spatial lag model and the dynamic spatial Doberman model for a brief analysis.

Analyzing the regression results in Table 6, it can be found that the estimated results of each variable is relatively consistent in the spatial lag model (SAR) and the spatial Dubin model (SDM) after considering the spatial lag explanatory variables. Specifically, the coefficient of total factor productivity TFP has passed the $5 \%$ significance level test and is positive, which shows that the increase of total factor productivity can promote the improvement of the modern economic system. This is because total factor productivity plays a decisive role in improving a country's economic strength and achieving its economic catch-up. The coefficients of the four control variables of industrial structure upgrading, factor marketization degree, environmental governance intensity, and degree of opening to the outside world are also significantly positive. This is because the modern economic system we want to build is a socialist market economic system and a modern industrial system. As the foundation and driven by modern technological progress, it will realize a sustainable economic system that optimizes industrial structure, efficiently allocates resources, and continuously upgrades product quality.

In the spatial Dubin model (SDM), the spatial correlation coefficient of total factor productivity is 0.0263 , which has passed the statistical test at the $1 \%$ level. In the dynamic spatial Dubin model (SDM_GMM), the spatial correlation coefficient of total factor productivity is 0.0741 , that is, for every $1 \%$ increase in the total factor productivity of neighboring regions, the perfection of the modern economic system in the region will increase by $0.0741 \%$. The reason that total factor productivity promotion of neighborhood can bring the region's modern economic system significant positive impacts mainly lies in the fact that the higher the total factor productivity, innovation, and competitiveness of the region economy, the more it will lead to the less developed areas to get experience from developed regions nearby to make appropriate adaptations, thus increasing the potential of economic development, and then accelerate the comprehensive construction of the modern economic system.

In the dynamic spatial lag model (SAR_GMM), when the $W_{1}$ spatial weight matrix is used, the estimated coefficient of time spillover effect of modern economic system perfection is 0.6127 , and the estimated coefficient of spatial spillover effect is 0.1048 , which are at statistical levels of $1 \%$ and $5 \%$, respectively. When the $W_{2}$ spatial weight matrix is used, the estimated coefficient of time spillover effect of modern economic system perfection is 0.4377 , and the estimated coefficient of spatial spillover effect is 0.1206 , which also passes the test at statistical levels of $1 \%$ and $5 \%$, respectively. On further investigation of the estimation results of the dynamic spatial Dubin (SDM_GMM) using two spatial weight matrices, it is also found that the estimated coefficients of the spatio-temporal spillover effect of the perfection of the modern economic system are all significantly positive. 
This means that the perfection of China's modern economic system has obvious characteristics of time and space spillovers. According to the empirical results, the time spillover effect is reflected in the improvement of the modern economic system of the previous period and the improvement of the current modern economic system. Correspondingly, spatial spillover effect produced in the improvement of the modern economic system of the neighboring area will lead to changes in the improvement of the modern economic system of the region in the same direction, that is, the improvement of the modern economic system of the region will increase with the improvement of the modern economic system of the neighboring area. At the same time, the robustness of the estimation results in this paper is also effectively tested by the consistency of the two dynamic space model parameter estimation signs.

\section{Conclusions and Recommendations}

This article first uses the DEA-Malmquist index method to calculate and decompose the total factor productivity of 30 provinces, municipalities, and autonomous regions in China from 2001 to 2017. Secondly, an indicator system from five dimensions of scale, structure, quality, technology, and environmental protection was constructed, and a comprehensive evaluation and analysis of the construction status of the modernized economic system of various provinces in China were carried out. Third, in addition to the traditional static spatial measurement model, this research also uses a dynamic spatial panel regression model that can examine dynamic characteristics and then further uses the systematic GMM two-step estimation to reduce the endogenous problems caused by error influence. The empirical evidence shows that China's 30 provinces, municipalities, and autonomous regions have little fluctuations in total factor productivity from 2001 to 2017, but they fluctuate greatly from a regional perspective; the overall level of China's modern economic system is relatively low, and the differences between provinces are large. The construction of a modern economic system is still in its infancy; the focus of the construction of a modern economic system is to continuously improve total factor productivity. In addition, in order to further improve the modern economic system, it is necessary to implement the concept of green development and optimize and upgrade the industrial structure, and efforts should be made in opening up and reforms in the marketization of factors, accelerating the optimization of the industrial structure, insisting on and improving the reform of the factor market, deeply practicing the concept of green development, and insisting on opening up to the outside world; forming a new pattern of comprehensive opening up can all play a positive role in improving China's modern economic system.

According to the conclusions of this research, the following suggestions are drawn: first of all, we must focus on the construction of modern economic systems in different regions. With the current rapid economic development, China's modern economic system has undergone tremendous changes. For the eastern region where the modern economic system is relatively well-developed, it is necessary to steadily develop and stay in line with western developed countries; for the western region where the modernized economic system is relatively low, it is necessary to intensify innovation, adhere to the new concept of green development, and cultivate the new driving force for green development that will never take the old path of first development and then transformation. When undertaking industrial transfer, the central and western regions also need to take advantage of their own resource endowments, adhere to an innovation-driven, factor-intensive development path, and resolutely refrain from developing high-energy-consumption and high-polluting industries [34, 35]. Second, we must ensure that the market plays a decisive role in the allocation of resources and handles the relationship between the government and the market in a scientific and reasonable manner. Activating production factors is the key to supplyside structural reforms. The purpose is to further activate the vitality of market entities, enable the free flow of factors in the market, and form a healthy and dynamic market with fair and orderly competition, the survival of the fittest by enterprises, and flexible price response to environment, and then improve the total factor productivity, so as to achieve a steady and continuous increase of national income [36]. Finally, put innovation at the core of the overall national development, and put the basis of development on innovation. Promote the in-depth integration of technological innovation and economic and social development, and form the vast majority of leading developments relying on innovation-driven and first-mover advantages. Of course, we must cultivate high-quality new labor talents, regard talents as the key element to support development, accelerate the formation of an economic system and development model with innovation as the main guidance and support, and promote the optimization of the industrial structure through technological progress, thereby improving the construction of a modern economic system [37, 38].

\section{Data Availability}

The data used to support the findings of this study are included within the article.

\section{Conflicts of Interest}

The authors declare that there are no conflicts of interest regarding the publication of this paper.

\section{Authors' Contributions}

Qin Tang, Zhi-An Ren, Kang-Feng Zhu, and Nai-ru Xu contributed equally to this paper.

\section{Acknowledgments}

This paper was supported by the Project of National Social Science Foundation of China (no. 19BJL015) and Anhui Provincial Quality Project in Colleges and Universities under Grant no. 2018ylzy074 and in part by Research Funds of Anhui Xinhua University under Grant no. 2018kyqd01. 


\section{References}

[1] Z. Liu, "Building a modern economic system: basic framework, key issues, and theoretical innovation," China Political Economy, vol. 2, no. 1, pp. 73-84, 2019.

[2] M. Akulich and J. Kaźmierczyk, "The socio-economic approach to the study of modern economic systems. Postcapitalism. Part 2," Management, vol. 22, no. 2, pp. 299-310, 2018.

[3] N. H. Gu and R. Tang, "Constructing a coordinated development industrial system compatible with the modern economic system," Journal of Jinan (Philosophy and Social Science Edition), vol. 39, no. 12, pp. 16-21+126, 2017.

[4] G. Q. He, "Socialist public ownership is the basis for building a modern economic system to achieve high-quality development," Journal of Western Forum, vol. 29, no. 3, pp. 1-33, 2019.

[5] W. H. Cai, "Historical materialism analysis of building a modern economic system: connotation, positioning and path," Journal of Contemporary World and Socialism, vol. 2020, no. 6, pp. 67-74, 2020.

[6] C. W. Zhao and H. M. Zhu, "How to understand the modern economic system," Journal of Ziguangge, vol. 2018, no. 3, pp. 25-27, 2018.

[7] J. S. Zhang, "Some understandings on the construction of a modern socialist economic system with Chinese characteristics in the new era," Journal of Economic Aspects, vol. 2018, no. 2, pp. 1-9, 2018.

[8] W. Liu, "Persist in the new development concept to build a modern economic system of socialism with Chinese characteristics," Social Sciences in Chinese Universities, vol. 2017, no. 6, pp. 13-18, 2017.

[9] J. X. Shi, K. W. Zhang, and Z. Y. Li, "The scientific connotation and construction focus of the modern economic system," Journal of Research on Financial Issues, vol. 2018, no. 2, pp. 22-31, 2018.

[10] R. N. A, "Origins of modern economic system: England or Holland," Journal of Žurnal Institucional'nyh Issledovanij, vol. 7, no. 3, pp. 50-63, 2015.

[11] I. V. Gashenko, S. G. Vokina, and D. G. Romanov, “Theoretical and methodological aspects of innovation development in modern economic systems," Journal of The Contemporary Economics, vol. 10, no. 4, pp. 363-372, 2016.

[12] J. L. Porket, Modern Economic Systems and Their Transformation, Palgrave Macmillan, London, UK, 1998.

[13] X. Y. He and K. R. Shen, "Modern economic system, total factor productivity and high-quality development," Journal of Shanghai Economic Research, no. 6, pp. 25-34, 2018.

[14] B. Feng, B. Wen, and H. X. Li, "The connotation, basis and path of the modern economic system," Journal of Reform, no. 6, pp. 71-79, 2018.

[15] A. Rezai, L. Taylor, and D. Foley, "Economic growth, income distribution, and climate change," Ecological Economic Papers, vol. 146, no. Apr, pp. 164-172, 2017.

[16] J. K. Gao and E. F. Cheng, "Building a modern economic system to achieve high-quality development," Journal of Academic Research, vol. 409, no. 12, pp. 73-82, 2018.

[17] E. F. Cheng and Q. Y. Chai, "Modern economic system: basic framework and realization strategy-learning from Xi Jinping's thoughts on building a modern economic system," Journal of Economic Research Reference, vol. 2855, no. 7, pp. 3-13+30, 2018.

[18] L. E. Li, Y. L. Wang, and Y. Y. Wang, "Construction and analysis of the evaluation index system of the modern economic system of the resource-based economy_- taking the comprehensive reform zone of the national resourcebased economy in Shanxi Province as an example," Journal of Economic Theory and Economic Management, vol. 2020, no. 7, pp. 100-112, 2020.

[19] Q. X. Zhou, "Evaluation of Guangzhou's construction of a modern economic system from the perspective of the Guangdong-Hong Kong-Macao Greater Bay Area," Journal of Reform and Strategy, vol. 35, no. 8, pp. 67-77, 2019.

[20] R. B. Zhong, "Research on the composition and evaluation of the modern economic system of urban agglomerations," Journal of the Party School of Shijiazhuang City Committee of the Communist Party of China, vol. 21, no. 11, pp. 25-32+42, 2019.

[21] F. Z. Xie, “China's economic development and development economics innovation," Journal of Social Sciences in China, vol. 40, no. 2, pp. 100-110, 2019.

[22] Y. S. Zhang and J. S. Liang, "Research on the index system of modern economic system," Journal of Macroeconomic Management, vol. 424, no. 4, pp. 17-24, 2019.

[23] T. Liu, "Research on the measurement and promotion path of hubei's modern economic system construction," Journal of Yangtze University (Social Science Edition), vol. 42, no. 3, pp. 42-46, 2019.

[24] W. Zou, "Building a modern economic system to achieve higher quality development," Journal of People's Forum-Academic Frontiers, vol. 2018, no. 2, pp. 31-38, 2018.

[25] Z. B. Cai, "Research on the modern economic system from the perspective of regional economy," Economist, no. 11, pp. 62-68, 2018.

[26] Z. A. Ren and H. Xing, "Difficulties and breakthrough strategies in the construction of the modern economic system in northern Anhui," Journal of Anhui University of Science and Technology, vol. 22, no. 2, pp. 13-22, 2020.

[27] P. Li, "Research on Shanghai's strategy of advancing the construction of a modern economic system," Journal of Scientific Development, vol. 2019, no. 6, pp. 5-15, 2019.

[28] A. Guha, D. Grewal, and P. K. Kopalle, "How artificial intelligence will affect the future of retailing," Journal of Retailing, vol. 97, no. 1, pp. 28-41, 2021.

[29] Z. B. Liu, "Important bottlenecks and policy priorities in the construction of a modern economic system," Journal of Economic Research Reference, vol. 2019, no. 12, pp. 104-111, 2019.

[30] K. Knaus and A. Hund, "Traditional inuit family structure and values as influenced by the modern economic system," Journal of The International Journal of Health, Wellness, and Society, vol. 5, no. 3, pp. 69-81, 2015.

[31] P. Y. Gao, C. Du, and X. H. Liu, "The construction of a modern economic system under the background of highquality development: a logical framework," Journal of Economic Research, vol. 54, no. 4, pp. 4-17, 2019.

[32] C. H. Gan, R. G. Zheng, and D. F. Yu, "The impact of China's industrial structure changes on economic growth and fluctuations," Journal of Economic Research, vol. 46, no. 5, pp. 4-16+31, 2011.

[33] H. Y. Lei, "Independent innovation, technology spillover, marketization degree and total factor productivity: an empirical analysis based on China's provincial panel data," Journal of Chongqing University of Technology (Social Sciences), vol. 32, no. 2, pp. 29-41, 2018.

[34] J. M. Zhu, Y. Chen, and S. Zhang, "Analysis of the impact of climate change on national vulnerability based on fuzzy 
comprehensive evaluation," Discrete Dynamics in Nature and Society, vol. 2020, Article ID 3527540, 10 pages, 2020.

[35] Y. X. Hong, "Start a new journey of modernization by building a modern economic system," Journal of Political Economics Review, vol. 9, no. 1, pp. 11-15, 2018.

[36] Z. B. Liu, "Building a modern economic system: the general program of economic construction in the new era," Journal of Shandong University, vol. 2018, no. 1, pp. 1-6, 2018.

[37] F. Xu, Y.-A. Du, and H. Chen, "Prediction of fish migration caused by ocean warming based on SARIMA model," Complexity, vol. 2021, Article ID 5553935, 9 pages, 2021.

[38] J. B. Liu, J. Zhao, and J. Min, "On the Hosoya index of graphs formed by a fractal graph," Fractals-Complex Geometry, Patterns, and Scaling in Nature and Society, vol. 27, no. 8, pp. 19-35, 2019. 